\title{
ERODIBILITAS TANAH (K) PADA BERBAGAI TUTUPAN LAHAN DI DESA BARU KECAMATAN SILAT HILIR KABUPATEN KAPUAS HULU
}

\author{
(Erodibility (K) at Various Covers in the Village Baru Silat Hilir District, Kapuas Hulu Regency)
}

\author{
Lidia Injilina, Tri Widiastuti, Joko Nugroho Riyono \\ Fakultas Kehutanan Universitas Tanjungpura, Jl. Daya Nasional Pontianak, 78124 \\ Email: Lidiainjilina@gmail.com
}

\begin{abstract}
Land degradation will result in widespread land damage, especially damage to forest land. Changes in land use from permanent vegetation to intensive agricultural land make the soil more easily eroded. One of the determining factors of erosion is soil erosion and soil cover vegetation. Soil erodiability is the average amount of soil lost each year per unit of the index, while the land cover is useful to protect the soil from the threat of damage by erosion and improve soil conditions. The research area located in Silat Hilir Sub-District of Kapuas Hulu Regency is a strategic area of the district from the point of economic importance. The Upper Kapuas Statistics Agency says there is a change in land use from year to year. The changes occurred not only in the increase in land use but also on changes in land use. The purpose and benefit of this research are to know the class of soil erodiability as well as to provide information on the class of land erodiability in The New Village of Silat Hilir District of Kapuas Hulu Regency. The value of soil erodiability is calculated using the Wischmeier and Smith formulas (1978) and determined based on the overlay of two maps, namely the land type map and the land cover map. Soil erodibility on various land cover in Silat Hilir Sub-District of Kapuas Hulu sub-district consists of 4 classes of land erodiability, among others: class 1 (very low), class 2 (low), class 4 (somewhat high), and class 5 (high).
\end{abstract}

Keywords: Erodibility, Land Cover, Soil

\section{PENDAHULUAN}

Tanah merupakan bagian penting dalam menunjang kehidupan makhluk hidup di muka bumi ini. Tanah sangat penting bagi kehidupan manusia. Tanah menyediakan nutrisi yang diperlukan tanaman untuk tumbuh dan dapat menyimpan air. Tanah dalam definisi ilmiah adalah kumpulan dari benda alam di permukaan bumi yang tersusun dalam horizon, terdiri atas campuran yang terbuat dari bahan mineral, bahan organik, air dan udara sebagai media untuk tumbuhnya tanaman (Hardjowigeno, 2007). Tanah yang rusak akan menyebabkan menurunnya kadar bahan organik serta unsur-unsur hara lainnya, karena menurunnya kadar bahan organik menyebabkan tanah menjadi labil akibat pukulan tetes air hujan dan aliran permukaan atau perluapan, sehingga air mudah menghancurkan dan mengangkutnya. Tanah yang kandungan bahan organiknya rendah, mudah tercerai berai karena daya ikat antar butir tanah rendah, sebab bahan organik dapat meningkatkan stabilisasi agregat tanah. Kerusakan tanah yang terjadi salah satunya disebabkan oleh degradasi lahan.

Terdegradasinya lahan akan mengakibatkan meluasnya kerusakan lahan terutama kerusakan lahan hutan. Perubahan penggunaan lahan dari vegetasi permanen menjadi lahan pertanian intensif 
menyebabkan tanah menjadi lebih mudah tererosi. Erosi menyebabkan hilangnya lapisan atas tanah yang subur dan baik untuk pertumbuhan tanaman serta berkurangnya kemampuan tanah untuk menyerap dan menahan air. Pada prinsipnya erosi tanah tidak dapat dihilangkan sama sekali atau (nol erosi), yang dapat dilakukan oleh manusia adalah memperkecil atau menekan erosi dengan tindakan konservasi.

Tutupan lahan berguna untuk melindungi tanah dari ancaman kerusakan oleh erosi dan memperbaiki kondisi tanah. Tanaman penutup tanah mempunyai peranan: (1) menahan atau mengurangi daya perusak butir-butir hujan yang jatuh dan aliran air di atas permukaan tanah, (2) menambah bahan organik tanah melalui batang, ranting dan daun mati yang jatuh, dan (3) menyerap air dan melakukan transpirasi. Peranan tutupan lahan ini dapat membantu memperkecil nilai erodibilitas tanah pada suatu lahan.

Erodibilitas tanah adalah daya tahan tanah terhadap proses penguraian dan pengangkutan oleh tenaga erosi (Morgan 1979 dalam Munadi 2008). Erodibilitas tanah merupakan jumlah tanah yang hilang rata-rata setiap tahun per satuan indeks. Faktor erodibilitas tanah menunjukan kekuatan partikel tanah terhadap pengelupasan dan transportasi partikel-partikel tanah oleh adanya energi kinetik air hujan. Besarnya erodibilitas tanah ditentukan oleh karakteristik tanah seperti tekstur dan struktur tanah, stabilitas agregat tanah, kapasitas infiltrasi, dan kandungan bahan organik serta bahan kimia tanah (Hardjowigeno, 1995).
Young et al (1990) dalam Suripin (2004) mengemukakan bahwa erodibilitas tanah merupakan sifat tanah yang dinamis yang bervariasi terhadap waktu, kelengasan tanah, suhu, pengolahan tanah gangguan manusia atau binatang, dan faktor biologi dan kimia.

Daerah penelitian yang terletak di Kecamatan Silat Hilir Kabupaten Kapuas Hulu merupakan kawasan strategis kabupaten, yang dimana kawasan agropolitan Silat Hilir dan sekitarnya merupakan kawasan strategis kabupaten dari sudut kepentingan ekonomi (PERDA Kabupaten Kapuas Hulu No 1 Tahun 2014). Desa baru adalah desa yang terletak di Kecamatan Silat Hilir dengan luas 65 $\mathrm{km}^{2}$ dan dari 13 Desa yang ada, Desa Baru termasuk kedalam desa dengan luas terkecil ke empat tetapi mempunyai jumlah penduduk terbanyak dalam urutan ke lima (Badan Statistik kabupaten kapuas hulu 2018). Badan Statistik Kapuas Hulu menyebutkan terjadi perubahan pengunaan lahan dari tahun ke tahun, salah satunya pada tahun 2017 luas tegal/kebun yang ada pada desa ini hanya seluas $1 \mathrm{Ha}$ dan meningkat pada tahun 2018 dengan luas 685 Ha. Perubahan yang terjadi tidak hanya pada peningkatan pengunaan lahan tetapi juga pada perubahan pengunaan lahan contohnya pada hutan rakyat, pada tahun 2014 Hutan Rakyat pada desa ini mempunyai luas $100 \mathrm{Ha}$ dan pada 2018 Hutan Rakyat itu sudah tidak ada lagi atau sudah dialih fungsikan untuk pengunaan lahan lain.

Berdasarkan rencana pembangunan kawasan strategis kabupaten untuk wilayah Kecamatan Silat Hilir perlu 
adanya penilaian tentang indikator lingkungan termasuk salah satunya erosi. Faktor penentu erosi adalah erodibilitas tanah dan penutupan lahan. Tujuan penelitian ini adalah untuk mengetahui nilai erodibilitas tanah pada berbagai tutupan lahan di Desa Baru Kecamatan Silat Hilir Kabupaten Kapuas Hulu sehingga dapat memberikan informasi dan sebagai masukkan terhadap prediksi erosi di Desa Baru Kecamatan Silat Hilir Kabupaten Kapuas Hulu.

\section{METODE PENELITIAN}

Penelitian dilaksanakan pada bulan Oktober 2019 sampai dengan Juni 2020. Pengambilan sampel tanah dilapangan dilakukan di bulan November 2019. Pengelolaan data awal serta lanjutan dilakukan di Fakultas Kehutanan Universitas Tanjungpura sedangkan untuk pengambilan sampel langsung dilakukan di Desa Baru Kecamatan Silat Hilir Kabupaten Kapuas Hulu.

Bahan yang digunakan dalam penelitian ini, adalah: Peta Administrasi Kecamatan Silat Hilir Kabupaten Kapuas Hulu, Peta Rupa Bumi Indonesia Lembar 1516-24 Nanga silat, Peta Sumberdaya Tanah Eksplorasi (Singkawang (NA49)), dan Peta Tutupan Lahan. Alat yang digunakan dalam penelitian ini antara lain: laptop, software GIS ( ArcGis 10.2), GPS type 64 s, kamera, plastik sampel, label sampel, ring sampel dan tally sheet.

Pelaksanaan penelitian dilakukan dalam empat (4) tahapan kerja yaitu: tahap persiapan, pengumpulan data, pengolahan data dan analisi data. Tahap persiapan dilakukan sebelum memulai kegiatan penelitian. Tahapan ini dimulai dari studi literatur serta mempersiapkan alat dan bahan yang digunakan dalam kegiatan penelitian. Setelah bahan yang diperlukan dalam kegiatan penelitian terpenuhi maka selanjutnya yang dilakukan adalah membuat Satuan Pemetaan Lahan /Land Mapping Unit (LMU). LMU didapatkan dari hasil tumpang susun/overlay dari 2 (dua) peta di Desa Baru Kecamatan Silat Hilir Kabupaten Kapuas Hulu, yaitu peta jenis tanah dan peta tutupan lahan dengan skala yang sama yaitu 1:50,000. Kedua peta yang telah dioverlay membentuk banyak polygon yang terdiri dari beberapa LMU dengan koordinat tempat yang berbeda di Desa Baru. Pemilihan LMU yang dijadikan sampel untuk penelitian ini dipilih berdasarkan aksesibilitas yang mudah agar waktu, biaya dan usaha dalam pengambilan sampel lebih efisien.

Pengumpulan data yang dilakukan dalam penelitian ini, terdiri dari pengumpulam data primer dan data sekunder. Data primer yang dikumpulkan antara lain adalah unsur tanah, unsur tanah yang diperlukan yaitu struktur tanah, tekstur tanah, bahan organik, dan permeabilitas tanah. Adapun data sekunder yang dikumpulkan dalam penelitian ini meliputi gambaran umum lokasi dan data pengunaan lahan pada Desa Baru Kecamatan Silat Hilir Kabupaten Kapuas Hulu.

Nilai erodibilitas tanah dihitung dengan menggunakan rumus Wischmeier dan Smith (1978) :

$$
\begin{aligned}
100 \mathrm{~K}= & 2,1 \mathrm{M}^{1,14}\left(10^{-4}\right)(12-\mathrm{a})+3,25(\mathrm{~b}-2) \\
& +2,5(\mathrm{c}-3)
\end{aligned}
$$

Keterangan :

$\mathrm{K}=$ erodibilitas tanah 
$\mathrm{M}=$ ukuran partikel (\% pasir halus $+\%$ debu) $\mathrm{X}$ (100 - \% liat) / (Tabel 3)

$\mathrm{a}=$ kandungan bahan organik

$\mathrm{b}=$ kelas struktur tanah (Tabel 1)

$\mathrm{c}=$ kelas kelas permeabilitas tanah (Tabel 2)

NB: Nilai M dapat juga diestimasi secara kasar dari tabel 3 apabila yang diketahui hanya kelas tekstur tanah. Penggunaan nilai $M$ untuk rumus $\mathrm{K}$ dalam tabel ini merupakan metode yang kurang akurat yang hanya digunakan apabila distribusi besaran butiran tidak diketahui. Dan untuk mengetahui kelas tekstur dapat digunakan segitiga tekstur (gambar 1).

Unsur tanah yang diperlukan dalam menghitung erodibilitas tanah yaitu struktur tanah, tekstur tanah, bahan organik, dan permeabilitas tanah. Pengambilan sampel tanah pada tiap-tiap LMU sampel diambil berdasarkan sampel tanah terganggu dan sampel tanah tidak terganggu. Sampel tanah terganggu digunakan dalam analisis struktur tanah, tekstur tanah, dan bahan organik tanah sedangkan sampel tanah tidak terganggu digunakan untuk menghitung permeabilitas tanah. Pengambilan sampel tanah terganggu dan tanah tidak terganggu dilakukan pada lokasi yang sama pada tiap-tiap LMU sampel.

Untuk sampel tanah tidak terganggu digunakan ring sampel dengan membersihkan lokasi pengambilan sampel dari serasah kemudian memasukkan ring sampel kedalam tanah sampai ring terisi penuh dengan tanah dan mengambil ring dengan cara mengali kedalam tanah kemudian ring sampel diberi kode sesuai LMU sampel. Untuk sampel tanah terganggu hanya mengambil tanah hasil dari galian ring sampel lalu langsung dimasukkan kedalam plastik sampel kemudian di beri kode sesuai LMU sampel.

Penilaian struktur dan permeabilitas tanah masing-masing menggunakan tabel berikut ini:

\section{Tabel 1. Penilaian Struktur Tanah (Soil Structure Assessment)}

\begin{tabular}{llc}
\hline No & Tipe struktur tanah & Kode penilaian \\
\hline 1 & Granular sangat halus (very fine granular) & 1 \\
2 & Granular halus (fine granular) & 2 \\
3 & Granular sedang dan besar (medium, coarse granular) & 3 \\
4 & Gumpal, lempeng, pejal (blocky, platty, massif) & 4 \\
\hline
\end{tabular}

Sumber: Sumber: Arsyad (2010)

Tabel 2. Penilaian Kelas Permeabilitas Tanah (Soil permeability Class Assessment)

\begin{tabular}{clcc}
\hline No. & \multicolumn{1}{c}{ Kelas permeabilitas tanah } & $\begin{array}{c}\text { Kecepatan } \\
(\mathrm{cm} / \mathrm{jam})\end{array}$ & Kode penilaian \\
\hline 1 & Cepat (rapid) & $>25.4$ & 1 \\
2 & Sedang sampai cepat (moderate to rapid) & $12.7-25.4$ & 2 \\
3 & Sedang (moderate) & $6.3-12.7$ & 3 \\
4 & Sedang sampai lambat (moderate to slow) & $2.0-6.3$ & 4 \\
5 & Lambat (slow) & $0.5-2.0$ & 5 \\
6 & Sangat lambat (very slow) & $<0.5$ & 6 \\
\hline
\end{tabular}

Sumber: Arsyad (2010) 
Tabel 3. Nilai M Dari Kelas Tekstur Tanah Yang Digunakan Untuk Rumus K (The M Value Of The Soil Texture Class Used For The Formula K)

\begin{tabular}{cllc}
\hline No. & Texture class (USDA) & Kelas Tekstur (USDA) & M Value (Nilai M) \\
\hline 1 & Sandy clay & Lempung pasiran & 1215 \\
2 & Light clay & Lempung ringan & 1685 \\
3 & Sandy clay loam & Geluh lempung pasiran & 2160 \\
4 & Silty clay & Lempung debuan & 2510 \\
5 & Clay loam & Geluh lempungan & 2830 \\
6 & Sand & Pasir & 3035 \\
7 & Loamy sand & Pasir geluhan & 3245 \\
8 & Silty clay loam & Geluh lempung debuan & 3770 \\
9 & Sandy loam & Geluh pasiran & 4005 \\
10 & Loam & Geluh & 4390 \\
11 & Silt loam & Geluh debuan & 6330 \\
12 & Silt & Debu & 8245 \\
\hline
\end{tabular}

Sumber:P.32/MENHUT-II/2009

Tabel 4. Klasifikasi Nilai K Tanah (Soil K Value Classification)

\begin{tabular}{ccc}
\hline Kelas & Nilai K & Harkat \\
\hline 1 & $0.00-0.10$ & Sangat Rendah \\
2 & $0.11-0.21$ & Rendah \\
3 & $0.22-0.32$ & Sedang \\
4 & $0.33-0.44$ & Agak Tinggi \\
5 & $0.45-0.55$ & Tinggi \\
6 & $0.56-0.64$ & Sangat Tinggi \\
\hline
\end{tabular}

Sumber: Arsyad 2010 dalam Ashari 2013

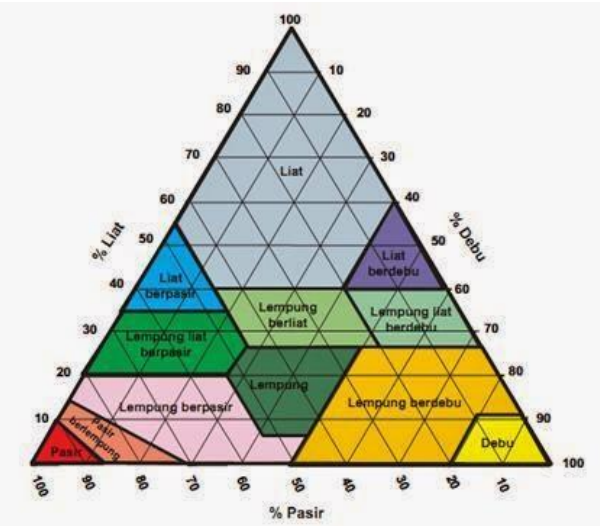

Gambar 1. Segitiga tekstur (Triangle Texture)

HASIL DAN PEMBAHASAN

\section{Hasil Penelitian}

Peta Jenis Tanah dan Peta Penutupan Lahan menjadi dasar pembuatan satuan pemetaan lahan atau Land Mapping Unit (LMU). LMU ditentukan melalui operasional tumpangsusun atau overlay Peta Jenis Tanah dan Peta Penutupan Lahan. Dari hasil overlay telah dihasilkan 35 polygon dengan 6 LMU. Untuk kawasan dengan penutupan lahan berupa pemukiman dan hutan rawa sekunder tidak dihitung nilai Erodibilitas Tanah (K) karena menurut Kartika dkk (2016) pemukiman yang memiliki nilai faktor $\mathrm{CP} 0$ dengan asumsi tanah $100 \%$ tertutup. 
Sedangkan, hutan rawa sekunder diasumsikan tidak memiliki laju erosi karena tanah pada hutan rawa sekunder hampir setiap waktu terendam dan tidak terkena limpasan air karena lokasi kontur rendah. Hasil penelitian dirincikan sebagai berikut:
Satuan Pemetaan Lahan/ Land Mapping Unit (LMU) di Desa Baru

Dari hasil tumpang susun kedua peta maka dihasilkan 35 polygon dengan 6 Satuan Pemetaan Lahan/ Land Mapping Unit (LMU) dengan luas masing-masing dapat dilihat pada tabel di bawah ini.

Tabel 5. Satuan Pemetaan Lahan ( Land Mapping Unit / LMU)

\begin{tabular}{ccccrr}
\hline \multirow{2}{*}{$\begin{array}{c}\text { No } \\
\text { LMU }\end{array}$} & \multirow{2}{*}{$\begin{array}{c}\text { LMU } \\
\text { sampel }\end{array}$} & Tutupan Lahan & Jenis Tanah & Ha & \multicolumn{1}{c}{ Luas } \\
\cline { 3 - 6 } & & Perkebunan & Enrisol & 508.54 & 7.82 \\
1 & PL4T1 & Pertambangan & Enrisol & 203.49 & 3.13 \\
2 & PL5T1 & Tanaman Campuran & Enrisol & 2132.28 & 32.80 \\
3 & PL6T1 & Perkebunan & Ultisol & 783.62 & 12.06 \\
4 & PL4T2 & Tanaman Campuran & Ultisol & 382.91 & 5.89 \\
5 & PL6T2 & Ultisol & 588.37 & 9.04 \\
6 & PL1T2 & Hutan Kering Sekunder & 588.37 & 2.27 \\
& \multicolumn{3}{c}{ Pemukiman } & 1498.90 & 23.06 \\
& Hutan Rawa Sekunder & & 399.52 & 6.15 \\
\hline
\end{tabular}

Sumber: Analisis Data Awal tahun 2020

LMU yang diambil sebagai sampel ditentukan dengan mempertimbangkan kemudahan aksesbilitas dalam pengambilan sampel agar waktu, biaya dan tenaga yang dikeluarkan lebih efisien. Nilai erodibilitas tanah dihitung dengan menggunakan rumus Wischmeier dan Smith (1978) dalam Asy-syakur (2008). Perhitungan nilai erodibilitas tanah dapat dilihat pada tabel berikut.

Tabel 6. Nilai Erodibilitas Tanah Pada LMU Sampel (Soil Erodibility Value In The Sampel Area)

\begin{tabular}{|c|c|c|c|c|c|c|c|c|c|c|}
\hline \multirow[b]{2}{*}{$\begin{array}{c}\text { No } \\
\text { LMU }\end{array}$} & \multirow[b]{2}{*}{$\begin{array}{c}\text { LMU } \\
\text { sampel }\end{array}$} & \multicolumn{3}{|c|}{ Tekstur (\%) } & \multirow{2}{*}{$\begin{array}{c}\text { Ukuran } \\
\text { Partikel } \\
\text { (M) }\end{array}$} & \multirow{2}{*}{$\begin{array}{l}\text { Bahan } \\
\text { Organi } \\
\text { k }(\%) \\
\text { (A) }\end{array}$} & \multirow{2}{*}{$\begin{array}{c}\text { Kelas } \\
\text { Struktuı } \\
\text { Tanah } \\
\text { (B) }\end{array}$} & \multirow{2}{*}{$\begin{array}{c}\text { Nilai } \\
\text { Permeabilitas } \\
\text { (C) }\end{array}$} & \multirow[b]{2}{*}{$\mathbf{K}$} & \multirow[b]{2}{*}{$\begin{array}{c}\text { Kelas } \\
\mathbf{K}\end{array}$} \\
\hline & & Pasir & Debu & Liat & & & & & & \\
\hline 1 & PL4T1 & 3.1 & 82.9 & 14 & 6330 & 2.93 & 3 & 6 & 0.52 & 5 \\
\hline 2 & PL5T1 & 5.41 & 72.59 & 22 & 6330 & 4.0 & 3 & 1 & 0.34 & 4 \\
\hline 3 & PL6T1 & 53.75 & 34.25 & 12 & 4005 & 2.16 & 3 & 5 & 0.35 & 4 \\
\hline 4 & PL4T2 & 7.8 & 68.2 & 24 & 6330 & 1.88 & 3 & 4 & 0.52 & 5 \\
\hline 5 & PL6T2 & 50.39 & 41.61 & 8 & 4005 & 4.90 & 3 & 1 & 0.17 & 2 \\
\hline 6 & PL1T2 & 56.94 & 33.06 & 10 & 4005 & 11.03 & 3 & 1 & 0.01 & 1 \\
\hline
\end{tabular}

Sumber: Analisis Laboratorium Fisika Tanah dan Laboratorium Kimia dan Kesuburan Tanah Fakultas Pertanian Universitas Tanjungpura tahun 2020.

Dari hasil analisis diatas Erodibilitas Tanah (K) pada Desa baru Kecamatan
Silat Hilir Kabupaten Kapuas Hulu terdapat 4 kelas erodibilitas tanah, antara 
lain: kelas 1 (sangat rendah) dengan tutupan lahan berupa hutan kering sekunder dan jenis tanah Ultisol, kelas 2 (rendah) dengan tutupan lahan berupa tanaman campuran dan jenis tanah Ultisol, kelas 4 (agak tinggi) dengan tutupan lahan berupa pertambangan dan tanaman campuran dengan jenis tanah Enrisol dan kelas 5 (tinggi) dengan tutupan lahan perkebunan dengan jenis tanah Enrisol dan Ultisol (luas area kelas erodibilitas tanah dapat dilihat pada lampiran).

Dari tabel tersebut menunjukkan bahwa presentase jumlah bahan organik wilayah penelitian termasuk rendah. Pengaruh bahan organik terhadap stabilitas struktur tanah mungkin merupakan peranan yang terpenting. Bahan organik berupa daun, ranting, dan sebagainya yang belum hancur, yang menutupi permukaan tanah merupakan pelindung tanah terhadap kekuatan perusak butir-butir hujan yang jatuh. Tanah yang kandungan bahan organiknya rendah, mudah tercerai berai karena daya ikat antar butir tanah rendah, sebab bahan organik dapat meningkatkan stabilisasi agregat tanah (Hasan dan Pahlevi 2017).

Kelas tekstur tanah pada lokasi penelitian berupa lempung, lempung berdebu dan lempung berpasir. Menurut Agus dkk (2006) Lempung mempunyai komposisi yang imbang antara fraksi kasar dan fraksi halus, dan lempung sering dianggap sebagai tekstur yang optimal untuk pertanian. Hal ini disebabkan oleh kapasitasnya menyerap hara pada umumnya lebih baik dari pada pasir. Tekstur berkaitan dengan kapasitas infiltrasi serta kemudahan tanah untuk terangkut pada saat terjadi erosi, sedangkan permeabilitas berkaitan dengan kemampuan tanah dalam meloloskan air. (Ashari, 2013).

\section{KESIMPULAN}

Hasil perhitungan Erodibilitas Tanah (K) di Desa Baru Kecamatan Silat Hilir Kabupaten Kapuas Hulu mempunyai nilai yang bervariasi antara lain, kelas 1 (sangat rendah) dengan tutupan lahan berupa hutan kering sekunder dan jenis tanah Ultisol, kelas 2 (rendah) dengan tutupan lahan berupa tanaman campuran dan jenis tanah Ultisol, kelas 4 (agak tinggi) dengan tutupan lahan berupa pertambangan dan tanaman campuran dengan jenis tanah Enrisol dan kelas 5 (tinggi) dengan tutupan lahan perkebunan dengan jenis tanah Enrisol dan Ultisol.

\section{SARAN}

Perhitungan nilai $\mathrm{K}$ akan lebih baik jika ukuran partikel (M) dihitung dengan rumus $\%$ pasir halus $+\%$ debu X (100 - \% liat) karena hasil akan lebih valid. Penggunaan nilai $\mathrm{M}$ untuk rumus $\mathrm{K}$ dalam tabel ini merupakan metode yang kurang akurat yang hanya digunakan apabila distribusi besaran butiran tidak diketahui. Hasil perhitungan ini akan membantu dalam menentukan perhitungan prediksi erosi di Desa Baru Kecamatan Silat Hilir Kabupaten Kapuas Hulu dan membantu dalam tindak konservasi tanah dilokasi tersebut.

\section{UCAPAN TERIMA KASIH}

Saya mengucapkan terima kasih banyak kepada dosen pembimbing dan penguji saya ibu Dra. Tri Widiastuti, M.Si, ibu Dra. Siti Latifah, M.Si, bapak Drs. Joko Nugroho Riyono, M.Si dan bapak Hafiz Ardian, S.Hut, M.P yang telah 
dengan sabar membimbing saya selama ini, dan tidak lupa pula saya ucapkan terima kasih kepada kedua orang tua saya dan saudara-saudara saya yang senantiasa selalu mendukung dan mendoakan saya, serta terimakasih kepada semua yang telah memberi bantuan dalam penelitian ini.

\section{DAFTAR PUSTAKA}

A'yunin Q. 2008. Prediksi Tingkat Bahaya Erosi Dengan Metode USLE di Lereng Timur Gunung Sindoro. Surakarta : Fakultas Pertanian Universitas Sebelas Maret.

Agus F, Yusrial, Sutono. 2006. Penetapan Tekstur Tanah Dalam Sifat Fisik Tanah Dan Metode Analisisnya Hal 43-62. Balai Penelitian Dan Pengembangan Pertanian, Kementerian Pertanian.

Arsyad S. 2010. Konservasi Tanah dan Air. Bogor : IPB Press.

Asdak C. 1995. Hidrologi dan Pengelolaan Daerah Aliran Sungai Cetakan Pertama. Bulaksumur, Yogyakarta : Gadjah Mada University Press.

Ashari A. 2013. Kajian Tingkat Erodibilitas Beberapa Jenis Tanah Di Pegunungan Baturagung Desa Putat Dan Nglanggeran Kecamatan Patuk Kabupaten Gunungkidul. Informasi, No. 1, XXXIX, Th. 2013.

Asy-syakur A. 2008. Prediksi Erosi Dengan Mengunakan Metode USLE Dan Sistem Informasi Geografis (SIG) Berbasis Piksel Di Daerah Tangkapan Air Danau Buyan. Pusat Penelitian Lingkungan Hidup (PPLH) : Universitas Undayana.
Badan Pusat Statistik. 2009-2018. Kapuas Hulu Dalam angka tahun 20092018. Kabupaten Kapuas Hulu Provinsi Kalimantan Barat.

Hardjowigeno, S. 2007. Evaluasi Kesesuaian Lahan \& Perencanaan Tataguna Lahan. Yogyakarta: Universitas Gajahmada.

Hasan H, Pahlevi R S. 2017. Zonasi Tingkat Erodibilitas Tanah Pada Area Reklamasi Tambang PT. Bharinto Ekatama Kabupaten Kutai Barat Kalimantan Timur. Samarinda: Fakultas Teknik Universitas Mulawarman.

Kartika I, Indarti I, Pudjojono M, Ahmad H. 2016. Pemetaan Tingkat Bahaya Erosi Pada Level Sub-Das: Studi Pada Dua Das Identik. Jurnal Agroteknologi Vol. 10 No. 01. Universitas Jember.

Munadi D. 2008. Erodibilitas Tanah Di Kecamatan Tanon Kabupaten Sragen Propinsi Jawa Tengah. Surakarta : Fakultas Geografi Universitas Muhammadiyah.

Singkawang NA49. 2000. Peta Sumberdaya Tanah Eksplorasi skala 1:1,000,000. Pusat Penelitian Tanah Dan Agroklimat.

Suripin. 2004., Pelestarian Sumber Daya Tanah danAir. Yogyakarta: Andi Offset.

Wischmeier WH, Smith DD. 1978. Predicting Rainfall Erosion Losses. A Guide to Conservation Planning. U. S Department of Agriculture, Agriculture Handbook No. 537. 


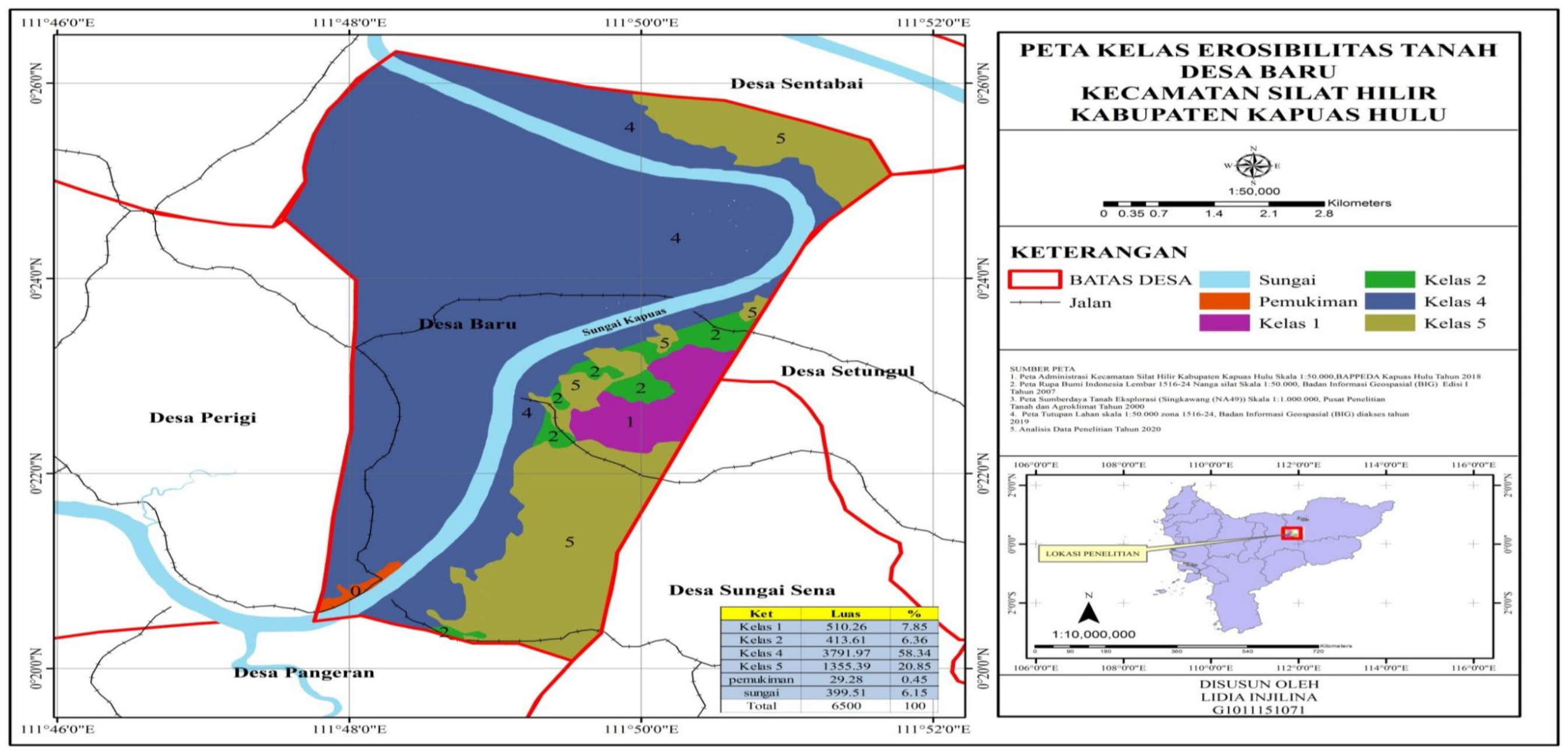

Gambar 2. Peta Kelas Erodibilitas Tanah Desa Baru Kecamatan Silat Hilir Kabupaten Kapuas Hulu (Soil Erodibility Class Map in the Village Baru Silat Hilir District, Kapuas Hulu Regency) 